University of Nebraska - Lincoln

DigitalCommons@University of Nebraska - Lincoln

Faculty Publications, Department of Psychology

Psychology, Department of

2010

Donor payoffs and other-regarding preferences in cotton-top tamarins (Saguinus oedipus)

Jeffrey R. Stevens

University of Nebraska-Lincoln, jstevens5@unl.edu

Follow this and additional works at: https://digitalcommons.unl.edu/psychfacpub

Part of the Psychiatry and Psychology Commons

Stevens, Jeffrey R., "Donor payoffs and other-regarding preferences in cotton-top tamarins (Saguinus oedipus)" (2010). Faculty Publications, Department of Psychology. 514.

https://digitalcommons.unl.edu/psychfacpub/514

This Article is brought to you for free and open access by the Psychology, Department of at DigitalCommons@University of Nebraska - Lincoln. It has been accepted for inclusion in Faculty Publications, Department of Psychology by an authorized administrator of DigitalCommons@University of Nebraska - Lincoln. 


\title{
Donor payoffs and other-regarding preferences in cotton-top tamarins (Saguinus oedipus)
}

\author{
Jeffrey R. Stevens \\ Center for Adaptive Behavior and Cognition, Max Planck Institute for Human Development, \\ Lentzeallee 94, 14195 Berlin, Germany
}

\begin{abstract}
Helping others at no cost to oneself is a simple way to demonstrate other-regarding preferences. Yet, primates exhibit mixed results for other-regarding preferences: chimpanzees and tamarins do not show these effects, whereas capuchin monkeys and marmosets preferentially give food to others. One factor of relevance to this no-cost food donation is the payoff to the donor. Though donors always receive the same payoffs regardless of their choice, previous work varies in whether they receive either a food reward or no food reward. Here, I tested cotton-top tamarins in a preferential giving task. Subjects could choose from two tools, one of which delivered food to a partner in an adjacent cage and the other of which delivered food to an empty cage. Thus, subjects could preferentially give or withhold food from a partner. I varied whether subjects received food payoffs, whether a partner was present or absent, and whether the partner was a non-cagemate or the subject's mate. Results showed that the subjects' overall motivation to pull either tool declined when they did not receive any food. Additionally, they did not preferentially donate or withhold food, regardless of their own payoff or their relationship with the partner. Thus, cotton-top tamarins do not take advantage of costfree food giving, either when they might gain in the future (mates) or when they have no opportunity for future interactions (non-cagemates).
\end{abstract}

Keywords: altruism, callitrichid, cooperative breeding, inequity, payoff, self-interest

\section{Introduction}

Self-interest lies at the heart of evolutionary and economic views of decision making. Evolutionary analyses of behavior predict that altruism (helping others at an expense to one's own fitness) will not spread through a population because non-altruists will have higher fitness. Behaviors that appear altruistic actually result in return benefits through various mechanisms such as reciprocity, kin selection, reputation formation, or punishment (Dugatkin 1997). Similarly, economic models assume that decision makers focusing on self-interest will outcompete altruists in the marketplace. In classical economic theory, an individual's utility function does not include payoffs to others (von Neumann and Morgenstern 1947). However, a rich literature in behavioral economics demonstrates that humans, in fact, do behave in ways that benefit others (Camerer 2003). Fehr and Schmidt (1999) present a model in which, rather than focusing exclusively on the payoffs to self, the outcomes of other agents factor into the utility functions of individuals. Once decision makers include the payoffs of others in their utility functions, they should attend to the outcomes of others and demonstrate "other-regarding preferences".

Recently, comparative psychologists have applied the behavioral economic framework, including a regard for the outcome of others, to non-human animals, especially primates. A study of cotton-top tamarins (Saguinus oedipus) showed that individuals spontaneously gave food to another unrelated individual in repeated reciprocity games, although this sharing decreased over time (Chen and Hauser 2005; Hauser et al. 2003). In addition, the 
tamarins rarely gave food to pure defectors, suggesting that any giving that occurred likely did not result from a general propensity to help others.

One way to test for other-regarding preferences in a more straightforward manner is to remove the costs associated with helping others. Stevens and Stephens (2004) tested this in blue jays (Cyanocitta cristata) by allowing them to give food to another individual at no cost to themselves. In this situation, individual subjects gave food in over $70 \%$ of the trials, whereas in a situation with a cost to cooperating (Prisoner's Dilemma), they gave food in less than $40 \%$ of the trials. Early work on cost-free generosity in primates, however, failed to show other-regarding preferences. Chimpanzees (Pan troglodytes), one of the most cooperative primate species (de Waal 2003; Melis et al. 2006a, b; Muller and Mitani 2005), did not demonstrate any regard for the food payoffs of other individuals. In two different tasks, chimpanzees could choose one of two options. Both options resulted in food rewards for the chooser, but only one option provided food to a partner. Chimpanzees failed to preferentially choose the option that delivered food to the partner when compared to a condition with no partner present (Jensen et al. 2006; Silk et al. 2005; Vonk et al. 2008).

Experiments with New World monkeys, however, have provided stronger evidence of other-regarding preferences. For example, in a study modeled after Silk et al. (2005), Burkart and colleagues (2007) showed that common marmosets (Callithrix jacchus) preferentially gave food to a partner when facing no cost. The authors proposed that cooperative breeding has provided a strong evolutionary force shaping other-regarding preferences, and this explains why marmosets and humans (Burkart and van Schaik 2009; Hrdy 2005) show these preferences but chimpanzees do not. This interpretation is, however, weakened based on the evidence that capuchin monkeys also show other-regarding preferences in similar tasks (de Waal et al. 2008; Lakshminarayanan and Santos 2008). Thus, cooperative breeding is not necessary for the evolution of other-regarding preferences. To further complicate the comparative data thus far and erode the significance of cooperative breeding, Cronin et al. (2009) conducted a similar test with the cooperatively breeding cotton-top tamarin, a New World monkey that shares many life history and anatomical traits with common marmosets. Tamarins failed to preferentially give food to their partners even with no cost, leading the authors to reject cooperative breeding as a sufficient factor in the evolution of other-regarding preferences.

One important aspect of other-regarding preferences is the role of food rewards for the potential donor. Though donors always receive the same payoffs regardless of their choice, the studies mentioned here vary in whether the donor receives a food payoff (Table 1). In some studies, subjects chose between $(1,0)$ and $(1,1)$ (payoff to donor, payoff to recipient), whereas in others, the donor received no payoff, instead choosing between $(0,0)$ versus $(0,1)$. Jensen et al. (2006) and Cronin et al. (2009) offered both types of donor payoffs and but across different experiments.

The present study investigates how the payoff to the donor influences his or her motivation to give food to the partner. To directly compare the effect of donor payoff on other-regarding preferences, I offered subjects both $(1,0)$ versus $(1,1)$ and $(0,0)$ versus $(0,1)$ choices in the same sessions. In addition, I compared a social condition to a non-social condition to control for the role of the presence of the partner. I also presented tamarins with an opportunity to give food when paired with either a genetically unrelated individual from a different group or their mate. Together, these factors explore how donor payoffs and partner relationships influence otherregarding preferences.

\section{Materials and Methods}

\section{Subjects}

I tested five cotton-top tamarins (two males) as subjects (ID, PB, EN, RB, SH) and seven tamarins (four males) as partners (ID, PB, RW, SP, EM, EN, RB). All subjects were adults (4-9 years old) housed at the Cognitive Evolution Laboratory at Harvard University and tested from June-November 2003. All subjects had participated in previous experiments, including a previous cooperation experiment (Hauser et al. 2003). In the first phase of the experiment, subjects were paired with non-cagemates of the opposite sex. Four subjects acted as non-cagemate partners for other subjects. In the second phase of the experiment, each subject was paired with his or her mate.

\section{Apparatus}

Experimenters lured subjects from their home cage to a transport cage with a raisin, and from the transport cage to a testing apparatus in a separate room. The apparatus consisted of three adjacent cages, each measuring approximately $30 \times 30 \times 30 \mathrm{~cm}$ (Figure 1a). The fronts of the cages were constructed from transparent Plexiglas panels, whereas the remaining sides were constructed from metal wire. The Plexiglas panels included doors with either one hole (side cages) or two holes (center cage). The experimenter placed the focal subject in the center cage and, for paired conditions, placed partners in a randomly chosen side cage. Removable transparent Plexiglas barriers separated the cages.

The experimenter placed two $45 \times 35 \mathrm{~cm}$ Plexiglas trays in front of the cages. Each tray included a small aluminum shelf stretching the width of the tray, with 
each end connected to a ball-bearing drawer slide. An acrylic handle was attached to each tray aligned with the holes in the subject's cage. Pulling the handle slid the shelf toward the subject and the adjacent cage.

\section{Experimental procedure}

All trials began with a transparent Plexiglas barrier preventing the subject from reaching the two handles. To begin a trial, the experimenter placed marshmallows on the metal shelf in the location determined by the trial type (see below and Figure 1b-e). The experimenter first placed the two sets of marshmallows in front of the subject ('inside' position) then in front of the partner ('outside' position). If the condition required no marshmallows in a given location, the experimenter simulated placing marshmallows there using the same movements in all trials. This avoided signaling the condition to the subjects, forcing them to attend to the distribution of food. After placing the food, the experimenter removed the front barrier, and the subject had $3 \mathrm{~s}$ to attempt to pull the handle and $30 \mathrm{~s}$ to get the food. If the subject did not touch the handle within $3 \mathrm{~s}$ or retrieve the food after $30 \mathrm{~s}$, the experimenter replaced the barrier and recorded the failure. Choice was measured as the first touch of a handle. After touching a handle, the experimenter slid the non-chosen handle out of reach. After the subject obtained the food, the experimenter drew the handle back to the initial position, replaced the barrier, and removed any unconsumed food.

\section{Trial types, conditions, sessions, and phases}

Subjects experienced four different trial types within every session (Figure 1b-e). In the "Self and Other" trials, the experimenter placed one marshmallow on each tray

Table 1. Food distributions and outcomes for previous experiments with nonkin

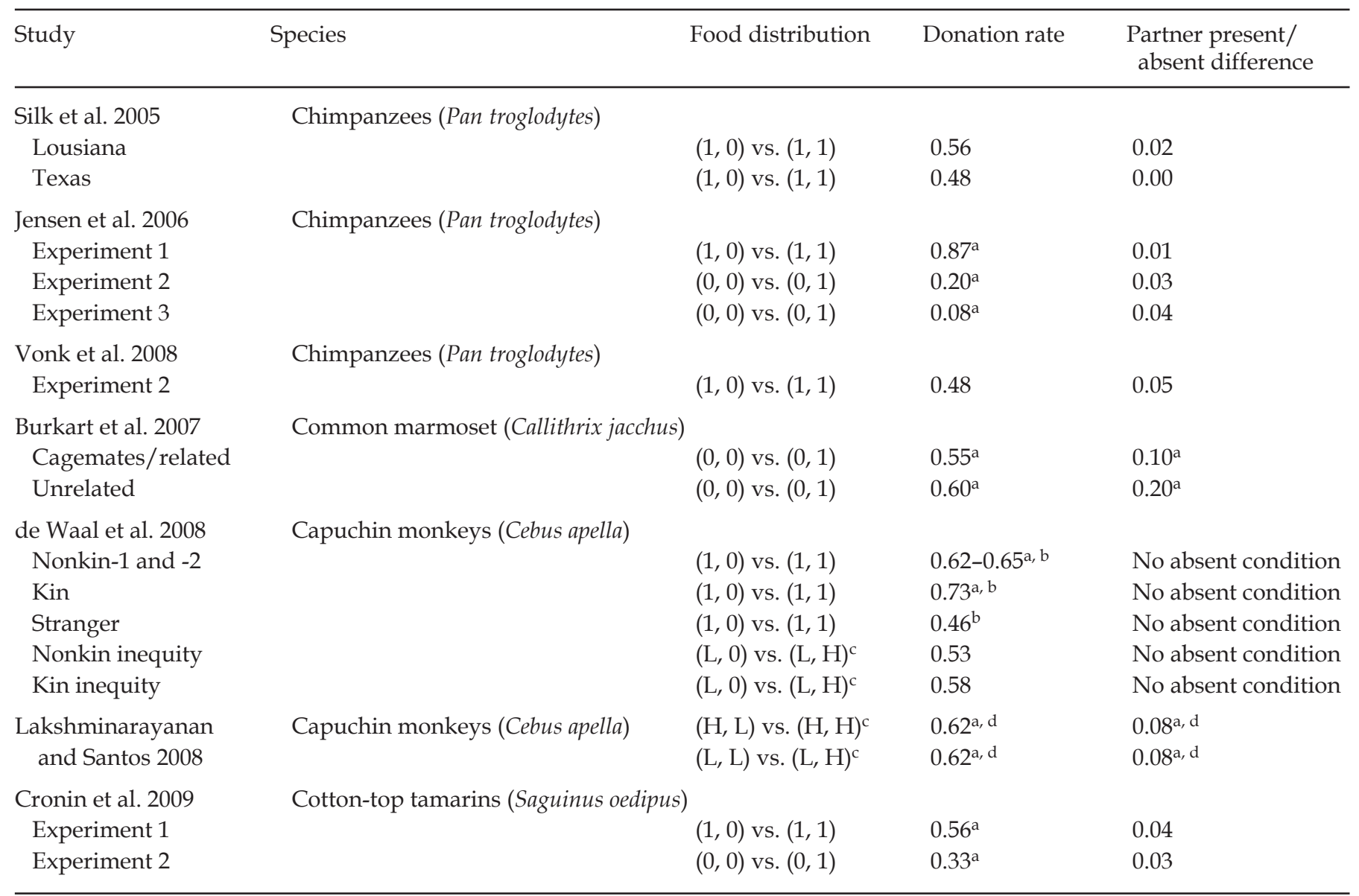

Means are taken directly from text or estimated from figures

a. Differs from chance ( 0.50 for donation rate and 0.0 for partner present/absent difference) at $\alpha=0.05$

b. Excludes data on individuals with side bias

c. $H$ high preferred reward (grape for de Waal et al. 2008, marshmallow for Lakshminarayanan and Santos 2008), L low preferred reward (apple for de Waal et al. 2008, celery for Lakshminarayanan and Santos 2008)

d. Though both conditions were conducted, performance did not differ across conditions, so only pooled mean was given in the text 


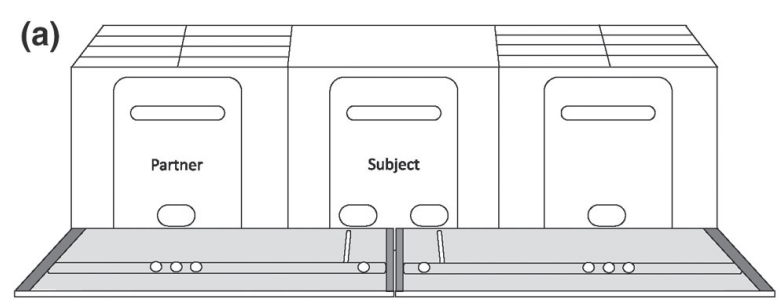

(b) Self and Other

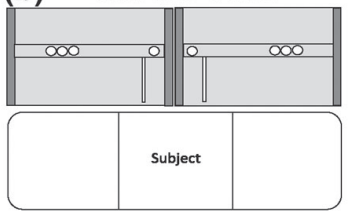

(d) Right Only

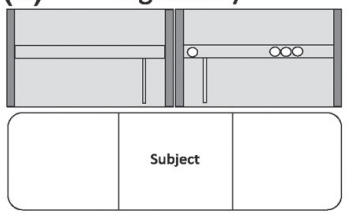

(c) Other Only

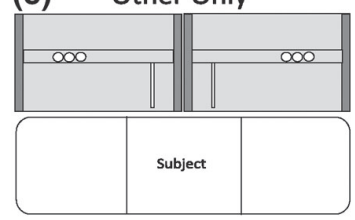

(e) Left Only

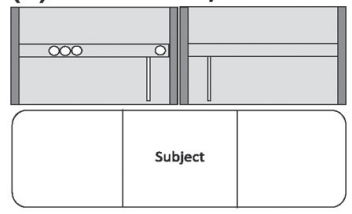

Figure 1. Apparatus and trial types. a) The apparatus consisted of three adjacent cages and two trays with handles accessible to the center cage. From the center cage, the subject could pull one of the two handles to deliver food to him- or herself and to either a partner or an empty cage. b) In Self and Other trials, food was placed in all four possible positions. Pulling the trays delivered food to self and to either the partner or an empty cage. c) In Other Only trials, food was placed only in the outside positions, so pulling the tray only delivered food to the partner or the empty cage. d) and e) In Right Only and Left Only trials, food was placed on only one of the two trays.

in front of the subject and three marshmallows in both of the outside locations. Three marshmallows were used in the outside position to maximize the subject's interest in those payoffs. In the "Other Only" trials, the experimenter placed three marshmallows in both of the outside locations but no marshmallows in front of the subject on the inside tray. The "Right Only" and "Left Only" trials presented the same one versus three marshmallow distribution as in Self and Other, but only on the right or left side of the apparatus. The one versus three design set up an inequity between partners, to which I return in the Discussion.

Subjects experienced three conditions. In the Partner Absent/Barrier condition, only the subject was tested with both cage barriers in place. In the Partner Absent/ No Barrier condition, only the subject was tested with one of the cage barriers removed, such that the subject could access food in both the inside and outside positions for that tray. In the Partner Present condition, the subject was tested with the partner placed in a randomly chosen side cage, and with the transparent barriers in place so that the tamarins could see each other, but not physically interact.

All sessions consisted of 14 trials. To facilitate the subject's ability to discriminate the different payoffs, the trial types followed a fixed order within a session. The first two trials were Right Only and Left Only trials, randomly ordered. The next four trials were Other Only trials, and the final eight trials were Self and Other trials. For the Self and Other trials in the Partner Absent/No Barrier condition, the side with the barrier was switched after four trials, so subjects had to track which side offered the highest payoffs.

For each of two phases (see below), subjects completed 10 replicates of the following series of sessions: a Partner Absent/Barrier session, then a Partner Absent/No Barrier session, then a Partner Present session. To pass a Partner Absent session, the subjects must have chosen correctly for all Right Only and Left Only trials. In no barrier sessions, they must have made no more than one mistake (meaning pulling the handle that delivers food behind barrier) in all Self and Other trials and Other Only trials. In barrier sessions, subjects could pull on no more than one Other Only trial but could pull either side on Self and Other trials. If a subject did not pass a session, it was repeated until the subject passed. In the first phase, subjects were paired with unrelated partners from another cage (non-cagemates). In the second phase, subjects were paired with their mates.

\section{Predictions}

If the tamarins have other-regarding preferences, they should preferentially pull the tool that gives food to their partner in both the Other Only and the Self and Other trials in the Partner Present condition. If they do not have other-regarding preferences, then they should pull the two tools at chance levels. It is also possible that they either act spitefully or perceive the payoffs as asymmetric, and then they may preferentially pull the tool associated with the empty cage. In addition, if the tamarins are motivated by altruism, then they should pull the tool more often for Other Only trials in the Partner Present condition compared to the Partner Absent/ Barrier condition. If, however, they do not show a difference in these conditions, this suggests that they either do not attend to or care about rewards for others. If the presence or absence of a payoff for themselves does not influence their decisions, they should donate equally frequently in the Other Only and Self and Other trials in the Partner Present condition. Finally, if they understand the apparatus and situation, they should preferentially pull for the open compartment in both the Other Only and the Self and Other trials in the Partner Absent/No Barrier condition. I use a significance level of $\alpha=0.05$ to test these predictions.

\section{Results}

In the non-cagemate phase, the tamarins pulled one of the two tools in almost every trial for all treatments in 
Figure 2. Pattern of pulling across conditions. a) Tamarins pulled one of the two tools in almost $100 \%$ of the trials in all conditions except the Other Only trials in both the Partner Absent/Barrier and Partner Present conditions. Pulling did not differ across these two conditions. b) To investigate whether the subjects preferentially pulled one of the tools, a 'correct' pull was defined differently depending on the condition. In the Partner Absent/Barrier condition, there is no partner present, and the subject cannot access either adjacent compartment. Since there is no correct response in this condition, pulling the right tool was randomly chosen as a correct response. In the Partner Absent/No Barrier condition, no partner was placed in the adjacent cage, but one of the barriers was removed to give access to the adjacent compartments. Thus, a correct pull was one which delivered food to the side with no barrier. In the Partner Present condition, a partner was present in one of the two adjacent compartments. Here, the trials in which the subject pulled the tool delivering food to the partner were scored as a correct choice. Error bars represent $95 \%$ confidence intervals.
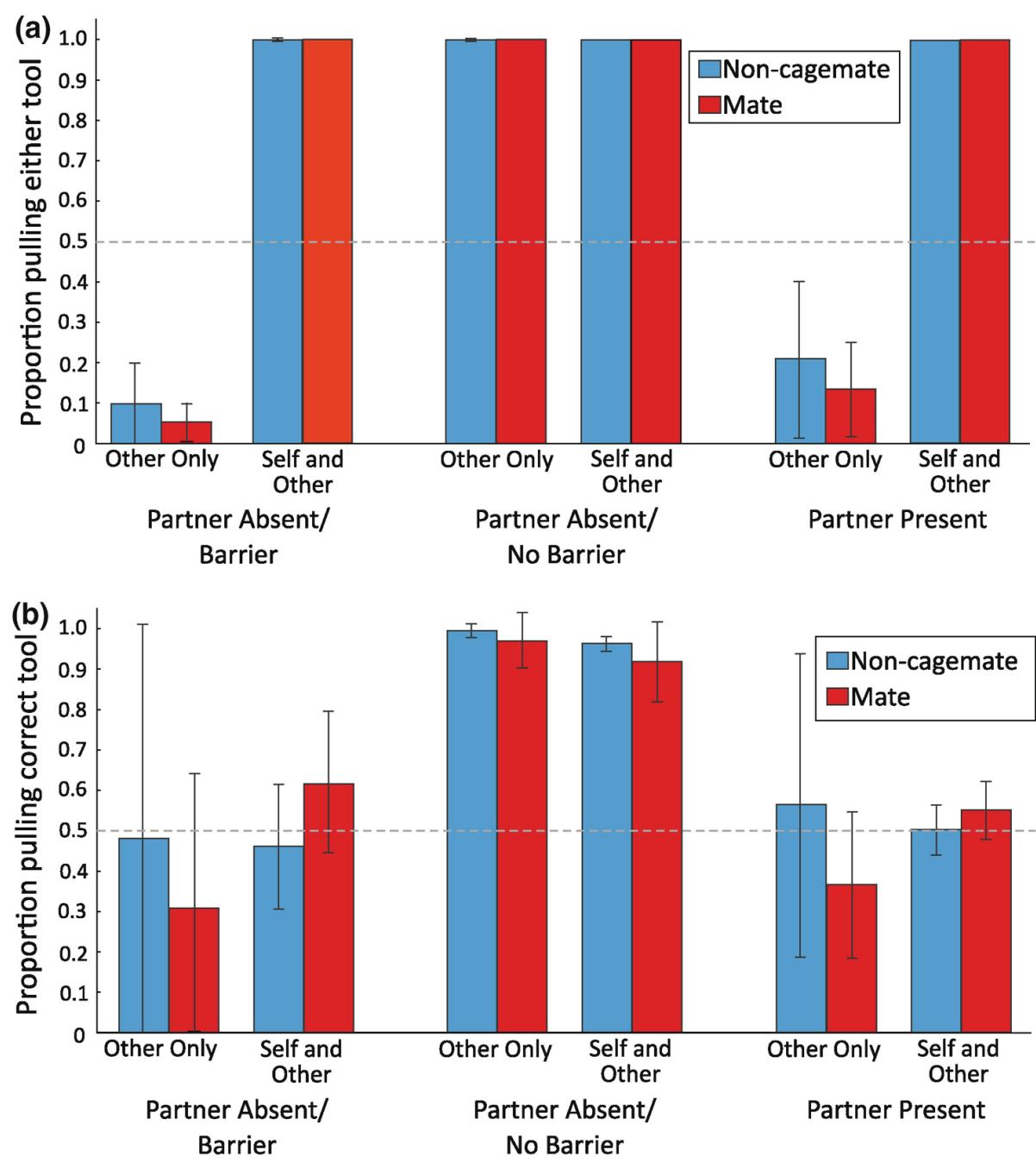

which food was available for them (Figure 2a). When food was not available for them (Other Only trials in Partner Absent/Barrier and Partner Present conditions), the mean $( \pm 95 \% \mathrm{CI})$ proportion of trials in which subjects pulled one of the two tools (overall pull rate pooled over subject means) dropped to $0.10 \pm 0.11$ in the Partner Absent/Barrier condition and $0.21 \pm 0.19$ in the Partner Present condition. They did not pull differently across these two conditions (paired $t$-test: $t_{4}=0.69, P=0.53$, $h=0.31$ ), indicating that the presence or absence of a partner did not influence their pulling. In the Partner Present condition, they pulled much less when they did not receive food, suggesting that donor payoffs greatly influenced their choice.

To investigate preferential food giving, I measured the proportion of trials in which the subject pulled the tray nearest the partner (number of pulls for partner/ total number of pulls), looking for a departure from chance performance of 0.50 (Figure 2b). For Self and Other trials in the Partner Present condition, the mean proportion of pulls for the non-cagemate partner was $0.50 \pm 0.06$, which did not differ from that expected by chance (one-sample $t$-test: $\mu=0.50, t_{4}=0.11, P=0.92$, $h=0.01)$. The proportion of pulls for the partner did not differ in the first and last five sessions (first half: $0.47 \pm 0.07$, second half: $0.54 \pm 0.07$ ). In Other Only trials in which subjects pulled one of the tools (only $21 \%$ of the trials), they preferentially pulled for their partner $0.56 \pm 0.38$ of the time, again, not differing from chance performance (one-sample $t$-test: $\mu=0.50, t_{4}=0.41$, $P=0.70, h=0.11)$ and not differing from the Self and Other trials (paired $t$-test: $t_{4}=0.40, P=0.71, h=0.11$ ). Thus, the subjects did not preferentially give food to their non-cagemate partners in the presence or absence of reward for themselves; when they did not receive food (Other Only trials), they rarely pulled at all.

To ensure that they understood the apparatus, I compared the Self and Other trials to the Other Only trials in the Partner Absent/No Barrier condition. The subjects correctly pulled the handle that delivered food to the adjacent compartment in almost every trial (Self and Other: $0.99 \pm 0.02$, Other Only: $0.96 \pm 0.02$; Figure $2 b$ ), indicating that they understood the apparatus.

In the cagemate phase, the overall pull rate was similar to the non-cagemate phase, with high pulling rates only for conditions in which food was available to the 
subject and low pull rates (Other Only in Partner Absent/Barrier: $0.05 \pm$ 0.04; Other Only in Partner Present: $0.14 \pm 0.12$ ) otherwise (Figure 2a). Preferential pulling for the subjects' mates in the Self and Other trials in the Partner Present condition was $0.55 \pm 0.07$, not differing from chance performance (one-sample $t$-test: $\mu=0.50, t$ ${ }_{4}=2.00, P=0.12, h=0.10$ ). The proportion of pulls for the partner did not differ in the first and last five sessions (first half: $0.55 \pm 0.15$, second half: $0.56 \pm 0.14$ ). In the Other Only trials in the Partner Present condition, subjects preferentially pulled for their mates in $0.36 \pm 0.18$ of the trials. Though subjects pulled less than expected by chance (one-sample $t$-test: $\mu=0.50, t$ $\left.{ }_{3}=-2.48, P=0.09, h=0.29\right)$, this is based on very few trials (28 of the 202 Other Only trials in the Partner Present condition) and is not a significant difference. Also, based on only a few trials, Other Only and Self and Other differ, although not significantly (paired $t$-test: $t_{3}=2.79$, $P=0.07, h=0.39$ ). Again, the subjects pulled correctly in the Partner Absent/No Barrier condition (Self and Other: $0.97 \pm 0.07$, Other Only: $0.92 \pm 0.10$; Figure $2 b$ ).

Though subjects did not differ from chance in the Self and Other trials for either the non-cagemate or mate phases, a comparison of these two phases shows a significant difference (paired $t$-test: $t_{4}=4.45, P=0.01$, $h=0.10$ ). In particular, four out of five subjects pulled slightly more (mean difference $=0.05$ ) for their mates than for non-cagemates (Table 2).

\section{Discussion}

To summarize, the tamarins always pulled one of the tools when they received food but rarely pulled when they did not receive food. Thus, they treated the situation quite differently depending on their own payoffs: a payoff for the donor motivated higher pulling rates. When the subjects did pull the tool, however, they did not preferentially give food to or withhold food from their partners in any conditions. The comparison between the non-cagemate to mate conditions did show a statistically significant effect of giving food more to mates. This result suffers from two difficulties, however. First, the effect is quite small (0.50 vs. 0.56), likely too small to be biologically meaningful. Second, all subjects in this experiment experienced the non-cagemate condition before the mate condition. Thus, it is possible that any differences between these two conditions could have resulted from the order in which they were experienced. The tamarins could have become more generous over time, biasing the later mate condition toward more generous behavior. Further tests with randomized ordering would address these issues.

One drawback of this experiment is the use of one food item for the subject and three food items for the partner. Though I used these amounts to increase the attention of the subject to the partner's payoff, this resulted in an inequality in the payoff distribution. Like the literature on other-regarding preferences, research on primates' ability to detect and respond to inequitable payoffs has resulted in conflicting accounts. Following Brosnan and de Waal's (2003) original study on capuchin monkeys, some studies have found that chimpanzees and capuchins demonstrate an aversion to inequity (Brosnan et al. 2005; van Wolkenten et al. 2007), whereas others have failed to find this effect in the same species (Bräuer et al. 2006; Dubreuil et al. 2006; Fontenot et al. 2007; Roma et al. 2006; Silberberg et al. 2009), including Brosnan and de Waal's (2003) male capuchin monkeys. If tamarins prefer equitable payoff distributions, this could explain why they did not preferentially give food in this experiment. This seems unlikely for two reasons, however. First, previous tests of inequity aversion in cotton-top tamarins did not show an effect of inequitable payoffs to partners (Neiworth et al. 2009). Second, if the tamarins wanted to avoid giving the larger amount to their partner, they should have preferentially withheld food from the partner. The tamarins exhibited complete indifference in their choices, however, suggesting that they simply did not attend to the payoffs of their partner. Nevertheless, it is possible that observing the partner receiving a larger payoff reduced the motivation of the subjects to the point that they became indifferent to the outcome of the partner.

These data replicate the negative results of Cronin et al. (2009), with cotton-top tamarins not giving food to or withholding food from other individuals. Like Cronin et al., these results conflict with the cooperative breeding hypothesis of other-regarding preferences proposed by Burkart et al. (2007). In this paradigm, the Other Only condition is analogous to the $(0,1)$ against $(0,0)$ condition used by Burkart et al. and Cronin et al. When the subject received no food, they rarely pulled either tool (5-21\% of trials) and exhibited no preferential pulling for the partner. Though common marmosets show generous behavior, it does not generalize to other cooperatively breeding callitrichid species. This combined with the data on the non-cooperatively breeding capuchins (de Waal et al. 2008; Lakshminarayanan and Santos 2008) suggests that cooperative breeding is neither necessary nor sufficient as an explanation of other-regarding preferences.

These data add to the currently conflicted state of studies on other-regarding preferences in primates (Yamamoto and Tanaka 2009). Humans, marmosets, and capuchins demonstrate other-regarding preferences, (Burkart et al. 2007; de Waal et al. 2008; Fehr et al. 2008; Lakshminarayanan and Santos 2008), but tamarins do not. To further complicate the situation, chimpanzees show preferences in some situations (Warneken et al. 2007; Warneken and Tomasello 2006) but not others (Jensen et al. 2006; Silk et al. 2005; Vonk et al. 2008). 
What underlies this variation? One obvious factor that could play an important role is food (Yamamoto and Tanaka 2009). Anecdotally for the tamarins, it appeared as though the presence of food for themselves prevented them from even attending to the payoffs for the partner. Yet, Lakshminarayanan and Santos found that capuchins preferentially gave food to partners even in the presence of food for themselves, so they clearly attended to the payoffs of their partner. Burkart et al. did not offer food to the marmoset subjects expressly to avoid the motivational problem of focusing on food for self and not attending to the food for others. Nevertheless, in the present experiment, even when the tamarins received no food for themselves and thus could not be distracted by this (Other Only trials), they rarely pulled at all and if they did pull, they did not differentiate between giving food to or withholding food from a partner. Though food may be important, it does not completely explain the pattern of data seen in primates. Presenting non-food rewards may, however, be useful in testing other-regarding preferences. The cases in which chimpanzees seem to show other-regarding preferences, for instance, are those in which they offer targeted helping rather than food (Warneken et al. 2007; Warneken and Tomasello 2006). Thus, testing non-food rewards may offer more instances of other-regarding preferences in primates.

In addition to food payoffs, the relationship with the partner could be quite relevant to other-regarding preferences. Though de Waal et al. (2008) found differences in donation rates for kin, nonkin, and strangers in capuchins, the data presented here, along with Burkart et al. (2007) and Cronin et al. (2009), suggest that tamarins and marmosets do not show differences between kin, nonkin, and mates. Takimoto et al. (2009) found differences for subordinates and dominants in capuchins, but this has not been tested in callitrichids.

One concern regarding the existing data on primate other-regarding preferences is the effect sizes of preferences. The marmosets in Burkart et al. (2007), for in- stance, only pulled for the partners in around $55-60 \%$ of the trials, and the capuchins pulled in 62 and $62-66 \%$ of the trials, respectively, in Lakshminarayanan and Santos (2008) and de Waal et al. (2008). The Jensen et al. (2006) results demonstrate the highest departure from chance performance of $50 \%$ (Table 1), but, critically, there is no difference between partner present and absent conditions in that experiment. For the experiments with positive results, the mean difference between partner present and partner absent conditions was 10-20 and 8\%, respectively, for Burkhart et al. and Lakshminarayanan and Santos (de Waal et al. did not include a partner absent condition-see Table 1). Though these overall donation rates and mean differences reach statistical significance, the effect is not as strong as one might expect if these species have a strong preference to help others: the biological significance of other-regarding preferences remains unclear.

Studies on other species demonstrate higher levels of no-cost donation. The blue jays playing a cooperative game donated food to their partner in about $74 \%$ of their trials (Stevens and Stephens 2004). Though they appear more cooperative than the primates tested so far, the methodology differs in the blue jay experiment. Both blue jay subjects made cooperative choices repeatedly, allowing cooperation contingent on their partner's behavior. The jays, in fact, did cooperate more often following their partner's cooperation than following defection. This potential element of reciprocity may have facilitated donation. Fehr et al. (2008) conducted an experiment on human children based on the primate experimental design. They showed that 3-6 year olds donated at rates around $60 \%$ (comparable to what we see with the primates), but 7-8 year olds donated in 78\% of trials, a clear demonstration of other-regarding preferences. Though not defined in the literature, I propose that other-regarding preferences should require a relatively high donation rate and consistent effects across individuals. Unfortunately, Burkhart et al. (2007) and de Waal et al. (2008) do not present individual data. Stud-

Table 2. Individual pulling rates and number of trials for select conditions

\begin{tabular}{|c|c|c|c|c|c|c|c|c|c|}
\hline \multirow[t]{2}{*}{ Subject } & \multirow[t]{2}{*}{ Sex } & \multicolumn{4}{|l|}{ Total pulling } & \multicolumn{4}{|c|}{ Preferential pulling ${ }^{\mathrm{a}}$} \\
\hline & & Non-cagemate & Mate & Non-cagemate & Mate & Non-cagemate & Mate & Non-cagemate & Mate \\
\hline EN & $\mathrm{F}$ & $0.11(44)$ & $0.11(57)$ & $0.18(40)$ & $0.20(40)$ & $0.43(40)$ & $0.38(40)$ & $0.55(80)$ & $0.61(80)$ \\
\hline $\mathrm{RB}$ & $\mathrm{F}$ & $0.12(101)$ & $0.05(57)$ & $0.40(40)$ & $0.22(37)$ & $0.69(40)$ & $0.22(37)$ & $0.49(80)$ & $0.49(77)$ \\
\hline $\mathrm{SH}$ & $\mathrm{F}$ & $0.03(48)$ & $0.06(36)$ & $0.33(40)$ & $0.19(42)$ & $0.46(40)$ & $0.50(42)$ & $0.43(80)$ & $0.49(78)$ \\
\hline Mean & & 0.10 & 0.06 & 0.21 & 0.14 & 0.56 & 0.36 & 0.50 & 0.55 \\
\hline
\end{tabular}

a. Preferential pulling for partner in trials in which the subjects pulled one of the two tools 
ies that do present individual data (Cronin et al. 2009; Lakshminarayanan and Santos 2008; Vonk et al. 2008) demonstrate high variability across subjects, with most subjects showing no differences between partner present and absent conditions (see also Table 2). In the absence of high donation rates and inter-individual consistency, perhaps these effects are more aptly labeled "other-regarding biases".

Acknowledgments - I am grateful for funding from the Ruth L. Kirschstein National Research Service Award (National Institutes of Health). I am particularly thankful to Marc Hauser for help in designing the experiment, for providing the facilities to run the experiment, and for comments on an early version of the manuscript. I appreciate feedback from three anonymous referees. I wish to thank Walt Gardner, Justus Meyer, Nina Strohminger, Heather Trevino, and Abby Wild for assistance in testing the tamarins, and I thank the members the Cognitive Evolution Laboratory at Harvard for valuable discussions about the project. This experiment was conducted in compliance with the Harvard University Animal Care protocols 92-16 and 22-07 and the APA Guidelines for Ethical Conduct in the Care and Use of Animals.

\section{References}

Bräuer J, Call J, Tomasello M (2006) Are apes really inequity averse? Proc R Soc Lond B 273:3123-3128

Brosnan SF, de Waal FBM (2003) Monkeys reject unequal pay. Nature 425:297-299

Brosnan SF, Schiff HC, de Waal FBM (2005) Tolerance for inequity may increase with social closeness in chimpanzees. Proc R Soc Lond B 272:253-258

Burkart JM, van Schaik C (2009) Cognitive consequences of cooperative breeding in primates? Anim Cogn 13:1-19. doi:10.1007/ s10071-009-0263-7

Burkart JM, Fehr E, Efferson C, van Schaik CP (2007) Other-regarding preferences in a non-human primate: Common marmosets provision food altruistically. Proc Nat Acad Sci USA 104:19762-19766

Camerer C (2003) Behavioral game theory: Experiments in strategic interaction. Princeton University Press, Princeton

Chen MK, Hauser M (2005) Modeling reciprocation and cooperation in primates: Evidence for a punishing strategy. J Theor Biol 235:5-12

Cronin KA, Schroeder KKE, Rothwell ES, Silk JB, Snowdon CT (2009) Cooperatively breeding cottontop tamarins (Saguinus oedipus) do not donate rewards to their long-term mates. J Comp Psychol 123:231-241

de Waal FBM (2003) The chimpanzee's service economy: Evidence for cognition-based reciprocal exchange. In: Ostrom E, Walker J (eds) Trust and reciprocity: Interdisciplinary lessons from experimental research. Russell Sage Foundation, New York, pp 128-143

de Waal FBM, Leimgruber K, Greenberg AR (2008) Giving is self-rewarding for monkeys. Proc Nat Acad Sci USA 105:13685-13689

Dubreuil D, Gentile SM, Visalberghi E (2006) Are capuchin monkeys (Cebus apella) inequity averse? Proc R Soc Lond B 273:1223-1228

Dugatkin LA (1997) Cooperation among animals: An evolutionary perspective. Oxford University Press, New York

Fehr E, Schmidt K (1999) A theory of fairness, competition, and cooperation. Q J Econ 114:817-868
Fehr E, Bernhard H, Rockenbach B (2008) Egalitarianism in young children. Nature 454:1079-1083

Fontenot MB, Watson SL, Roberts KA, Miller RW (2007) Effects of food preferences on token exchange and behavioural responses to inequality in tufted capuchin monkeys, Cebus apella. Anim Behav 74:487-496

Hauser MD, Chen MK, Chen F, Chuang E (2003) Give unto others: Genetically unrelated cotton-top tamarin monkeys preferentially give food to those who altruistically give food back. Proc R Soc Lond B 270:2363-2370

Hrdy SB (2005) Evolutionary context of human development: The cooperative breeding model. In: Carter CS, Ahnert L, Grossmann KE, Hrdy SB (eds) Attachment and bonding: A new synthesis. (vol. 92). MIT Press, Cambridge, pp 9-32

Jensen K, Hare B, Call J, Tomasello M (2006) What's in it for me? Self-regard precludes altruism and spite in chimpanzees. Proc R Soc Lond B 273:1013-1021

Lakshminarayanan VR, Santos LR (2008) Capuchin monkeys are sensitive to others' welfare. Curr Biol 18:R999-R1000

Melis AP, Hare B, Tomasello M (2006a) Chimpanzees recruit the best collaborators. Science 311:1297-1300

Melis AP, Hare B, Tomasello M (2006b) Engineering cooperation in chimpanzees: Tolerance constraints on cooperation. Anim Behav 72:275-286

Muller MN, Mitani JC (2005) Conflict and cooperation in wild chimpanzees. Adv Stud Behav 35:275-331

Neiworth JJ, Johnson ET, Whillock K, Greenberg J, Brown V (2009) Is a sense of inequity an ancestral primate trait? Testing social inequity in cotton top tamarins (Saguinus oedipus). J Comp Psychol 123:10-17

Roma PG, Silberberg A, Ruggiero AM, Suomi SJ (2006) Capuchin monkeys, inequity aversion, and the frustration effect. J Comp Psychol 120:67-73

Silberberg A, Crescimbene L, Addessi E, Anderson J, Visalberghi E (2009) Does inequity aversion depend on a frustration effect? A test with capuchin monkeys (Cebus apella). Animal Cognition 12:505-509

Silk JB, Brosnan SF, Vonk J, Henrich J, Povinelli DJ, Richardson AS, Lambeth S, Susan A, Mascaro J, Shapiro S (2005) Chimpanzees are indifferent to the welfare of unrelated group members. Nature 437:1357-1359

Stevens JR, Stephens DW (2004) The economic basis of cooperation: Trade-offs between selfishness and generosity. Behav Ecol 15:255-261

Takimoto A, Kuroshima H, Fujita K (2009) Capuchin monkeys (Cebus apella) are sensitive to others' reward: An experimental analysis of food-choice for conspecifics. Animal Cognition. doi:10.1007/s10071-009-0248-6

van Wolkenten M, Brosnan SF, de Waal FBM (2007) Inequity responses of monkeys modified by effort. Proc Nat Acad Sci USA 104:18854-18859

von Neumann J, Morgenstern O (1947) Theory of games and economic behavior, 2nd edn. Princeton University Press, Princeton

Vonk J, Brosnan SF, Silk JB, Henrich J, Richardson AS, Lambeth SP, Henrich J, Shapiro S, Richardson A, Lambeth S, Povinelli DJ (2008) Chimpanzees do not take advantage of very low cost opportunities to deliver food to unrelated group members. Anim Behav 75:1757-1770

Warneken F, Tomasello M (2006) Altruistic helping in human infants and young chimpanzees. Science 311:1301-1303

Warneken F, Hare B, Melis AP, Hanus D, Tomasello M (2007) Spontaneous altruism by chimpanzees and young children. PLoS Biol 5:e184

Yamamoto S, Tanaka M (2009) How did altruism and reciprocity evolve in humans? Interact Stud 10:150-182 